\title{
Types, Topics and Trends: A Ten-Year Review of Research Journals in Science Education
}

\author{
John Mitchell O'Toole *, Margaret Freestone, Karina S. McKoy and Brian Duckworth
}

School of Education, Faculty of Arts and Education, The University of Newcastle, Callaghan, NSW 2308, Australia; margaret.freestone@newcastle.edu.au (M.F.); karina.mckoy@newcastle.edu.au (K.S.M.); brian.duckworth@uon.edu.au (B.D.)

* Correspondence: mitch.otoole@newcastle.edu.au

Received: 24 April 2018; Accepted: 11 May 2018; Published: 18 May 2018

\begin{abstract}
All reviews are selective and this one restricts itself to content analysis of articles published between the beginning of 2005 and the end of 2014 in the premier, generalist, Science-education, research journals: International Journal of Science Education; Journal of Research in Science Teaching; Research in Science Education; Science Education, and Studies in Science Education. The analysis relies on coding of over 2000 abstracts in terms of research method, educational level, disciplinary context and research topic. Articles were tallied within each category for each journal to produce ranks indicating the relative output for that category. Presentation of results in two five-year spans (2005-2009 and 2010-2014) allows comment on variations in output across the ten years reviewed. Such broad reviews provide a useful spur to expert reflection while also mapping the field for novices attempting to enter it. A discussion of the themes of this Special Issue: Interactive Simulations and Innovative Pedagogy for Conceptual Understanding in Science Education provides one example of such use. The paper closes with a comparison with existing reviews and suggestions for further work. This research literature has claims to wider relevance because of its location on the boundary between Science and the Humanities.
\end{abstract}

Keywords: research review; science education journals; content analysis

\section{Introduction}

Curriculum change is a recurring phenomenon in education. In 2009, a K-12 school in eastern Australia noted that local changes were likely as part of a renewed attempt to produce a national curriculum. They approached the first author with the request that their experienced, long-term staff be brought up to date on contemporary developments in science education, anticipating that this would better equip the school to respond appropriately to the changing jurisdictional context.

This request led to a survey of documents surrounding the then-current phase of the local curriculum debate, together with a review of post-2004 publications in the local research journal (Research in Science Education: RiSE), and the national and state professional journals (Teaching Science and Science Education News, respectively). This represented a pragmatic decision to 'drill down' through resources to which the specific audience would have relatively ready access, in contrast to an automated search through digital databases.

The pattern of research emerging from that pragmatic review appeared to be particularly useful as such patterns could identify work of current interest and locate research gaps. This seemed to suggest a broad survey; based on coding, counting and comparing the abstracts of articles published in journals that were more representative of the field. Such broad surveys form solid foundations for more focused reviews, forming the 'map' that guides the selection of locations for 'photographs' of particular terrain. 
This literature has claims to wider interest within the research community because of its location on the boundary between 'two cultures' [1] and the consequent light that patterns within it may throw on subsequent consideration of wider issues of methodology, language and publication.

\section{Previous Reviews of the Field}

Science Education research has already been the subject of reviewer work. In one sense, the journal Studies in Science Education (SSE) provides an on-going detailed review of this field, as topics chosen for review within it represent editor and researcher perceptions of areas of interest within that scholarly community. Detailed discussion of SSE appears below, as that journal formed part of the wider survey documented here. There have also been a number of separate published reviews of the entire field, which took either a manual or an automated approach. Earlier reviews provide incidental support for the present study's choice of journals [2] and use of abstracts [3].

The manual approach resembles the process of the limited initial review described above. The solution to some emerging problem seems to require illumination of accessible and/or important previous work and so the reviewer selects appropriate resources and examines them in some detail. Some motivating problems have been issues of methodology [4-6], publication [7], author origins [8] and a desire to comprehend the field as a whole within particular jurisdictions [9]. A desire to "provide more information for the growing international aspect of science education research" with a subsequent focus on "the variations of the methodologies used and the research topics chosen" (8) motivated the Tsai group, whose work provides an extended example of this approach $[8,10,11]$. Reviews have more recently used computer-based search approaches that rely on multi-stage clustering techniques [2,3]. Clustering broadly resembles the grounded approaches utilised in qualitative research: automated analysis of the journals produces emergent themes, manual checking of which precedes location of common areas identified by common citations across articles.

This paper seeks to extend that existing work by exposing the areas of greatest concentration in broadly contemporary science education research, illuminating the areas with potential for further work and identifying those parts of the field that may be diminishing in importance. The intertwined issues of teaching strategy, ICT and constructivism provide the context for an initial example of identification of useful initial sources and potential final destinations for work such as that comprising the other articles in this Special Issue. Comparison of the results of the present study with previous work $[2,3,8,10,11]$ occurs towards the end of this paper, which responds to recent calls for more accessible replications of research [4]. The broad mapping exercise that forms the foundation of this paper will inform deeper subsequent work, such as that the authors are currently doing within the fields of scientific literacy, in particular, and the review process, in general.

This study seeks to answer the following specific questions:

1. Does such an abstract-based, 'drill down' through representative journals provide an illuminative account of this field of research?

2. What diversity in the form and function of abstracts is apparent across these journals dealing with research in science education?

3. What diversity in research focus is apparent between these journals?

4. Which topics for research exhibit increasing publication across these ten years?

5. Which topics for research exhibit decreasing publication across these ten years?

6. Which issues emerge from the broad survey that might reward more focused reviews?

\section{Materials and Methods}

The 2009 request with which this work began provided the first author with a five-year review of the local science educator and teacher journals, based on reading both abstract and text. The opportunity provided by a 2010 conference presentation [12] prompted expansion of the survey. It soon became clear that a useful survey would need to be comprehensive. If that was to be feasible, 
the scope of the survey would need to be limited. The initial survey indicated substantial consistency between the abstracts and texts of the 150 coded articles from Research in Science Education (RiSE). This should be unsurprising, as journal editors would presumably reject articles whose abstracts misrepresent their contents.

Therefore, it was decided to restrict this review to article abstracts, so matching initial phases of both 'systematic review' [5] and 'qualitative synthesis' [13]. Use of abstracts is characteristic of surveys aspiring to be large-scale [2] and a feature of other content analyses [3,14-16]. This survey restricts itself to publication in general research journals in the science education field, leaving aside the interesting interaction between their contents and that of teacher journals; and neglecting otherwise valuable, more focused journals such as Science and Education or the Australasian Journal of Educational Technology. The reviewers decided to use the categories that emerged from the initial 2009 survey as a tentative guide for subsequent analysis and, while the present review surveys journal contents, it does not seek to evaluate their relative qualities. The period surveyed inevitably involved changes in editorial control, particular focus and publication rates, which influenced the changes emerging from the analysis. Such diversity represents part of the analyzed data, rather than variables confounding any supposed evaluation of the journals.

\subsection{Journals}

This decision led to analysis of the Journal of Research in Science Teaching (JRST), Science Education (ScEd), Studies in Science Education (SSE), International Journal of Science Education (IJSE) and Research in Science Education (RiSE); all of which exhibit international reach and reputation, relatively high impact factors and long-term influence (see Notes to Table 1). The paper escapes the plausible charge of representing another "glaring example of parochialism" [17] through its modest intention to broadly map the field within which those journals wield most influence: Science Education research. Contemporary precedents $[10,18]$, led to the exclusion of editorials, commentaries, responses and book reviews, leaving only articles with an abstract to be included in the present mapping.

\subsection{Coding the Text Sample}

The abstracts of 2294 articles were analysed, 955 published between 2005 and 2009 and 1339 articles published between 2010 and 2014. "Any singled-authored account is necessarily selective and idiosyncratic" [19] and consequently four people were involved in this coding. The analysis was crosschecked and harmonized three times as it expanded, following the practice of previous reviewers [20,21].

The modified analysis category sheet that forms Appendix A to this paper preserves the detail of the framework used in the study. A separate MSWord ${ }^{\odot}$ file was generated for each journal, linked with Endnote $^{\odot}$ and an in-text reference appropriate to the relevant sub-category was inserted (indicated

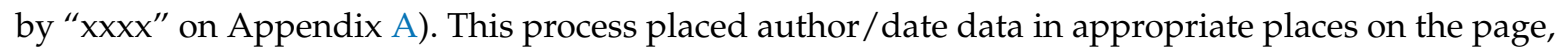
generated an expanding reference list at the end of each file and produced a database of bibliographic detail for the five journals across the ten years in question, linked to PDF files of the articles themselves. The final form of the analysis category file contained three 'Types' of research and five 'Topic' categories, divided into more than 100 sub-categories, including 'Strategies', 'ICT' and 'Constructivism', which will be the focus of discussion later in this paper. Coding placed abstracts into more than one sub-category if their content suggested it.

A count of the in-text references in each section yielded a publication number (e.g., 23 articles dealing with 'conceptual change' published in IJSE between 2005 and 2009) and addition of those numbers yielded the total for that sub-category within that journal (e.g., 103 articles dealing with 'constructivism'). A tally of these sub-categories yielded counts for each category (e.g., 240 articles coded as dealing with 'Learning' published in IJSE during that first 5-year span: see Appendix C). A tally of journal categories yielded overall total counts for each journal (see Table 1). 
Table 1. Broad coding categories by Journal ${ }^{1}$.

\begin{tabular}{|c|c|c|c|c|c|c|c|c|c|c|c|c|c|c|c|c|c|c|}
\hline \multirow{2}{*}{ Category } & \multicolumn{6}{|c|}{ JRST $^{2}$} & \multicolumn{6}{|c|}{$\mathrm{ScEd}^{3}$} & \multicolumn{6}{|c|}{$\mathrm{SSE}^{4}$} \\
\hline & $A^{7}$ & $R^{9}$ & B $^{8}$ & $R^{9}$ & Total & $R^{9}$ & $A^{7}$ & $R^{9}$ & $\mathbf{B}^{8}$ & $R^{9}$ & Total & $R^{9}$ & $A^{7}$ & $R^{9}$ & $\mathbf{B}^{8}$ & $R^{9}$ & Total & $R^{9}$ \\
\hline $\begin{array}{c}\text { Type: } \\
\text { Method }\end{array}$ & $\begin{array}{l}236^{10} \\
94.40 \%\end{array}$ & 1 & $\begin{array}{c}251 \\
100 \%\end{array}$ & 1 & $\begin{array}{c}487 \\
97.20 \%\end{array}$ & 1 & $\begin{array}{c}233 \\
100 \%\end{array}$ & 1 & $\begin{array}{c}161 \\
78.16 \%\end{array}$ & 1 & $\begin{array}{c}394 \\
91.84 \%\end{array}$ & 1 & $\begin{array}{c}22 \\
100 \%\end{array}$ & 1 & $\begin{array}{c}31 \\
100 \%\end{array}$ & 1 & $\begin{array}{c}53 \\
100 \%\end{array}$ & 1 \\
\hline Level & $\begin{array}{c}207 \\
82.80 \%\end{array}$ & 2 & $\begin{array}{c}187 \\
74.50 \%\end{array}$ & 2 & $\begin{array}{c}394 \\
78.64 \%\end{array}$ & 2 & $\begin{array}{c}164 \\
70.38 \%\end{array}$ & 2 & $\begin{array}{c}134 \\
65.05 \%\end{array}$ & 2 & $\begin{array}{c}298 \\
69.46 \%\end{array}$ & 2 & $\begin{array}{c}1 \\
4.54 \%\end{array}$ & 3 & $\begin{array}{c}17 \\
54.84 \%\end{array}$ & 2 & $\begin{array}{c}18 \\
33.96 \%\end{array}$ & 2 \\
\hline Discipline & $\begin{array}{c}103 \\
41.20 \%\end{array}$ & 3 & $\begin{array}{c}99 \\
39.44 \%\end{array}$ & 3 & $\begin{array}{c}202 \\
40.32 \%\end{array}$ & 3 & $\begin{array}{c}104 \\
44.64 \%\end{array}$ & 3 & $\begin{array}{c}71 \\
34.47 \%\end{array}$ & 3 & $\begin{array}{c}175 \\
40.79 \%\end{array}$ & 3 & $\begin{array}{c}5 \\
22.73 \%\end{array}$ & 2 & $\begin{array}{c}5 \\
16.13 \%\end{array}$ & 3 & $\begin{array}{c}10 \\
18.87 \%\end{array}$ & 3 \\
\hline $\begin{array}{c}\text { Topic: } \\
\text { ScLiteracy }\end{array}$ & $\begin{array}{c}242 \\
96.80 \%\end{array}$ & 1 & $\begin{array}{c}168 \\
66.93 \%\end{array}$ & 1 & $\begin{array}{c}410 \\
81.84 \%\end{array}$ & 1 & $\begin{array}{c}109 \\
46.78 \%\end{array}$ & 1 & $\begin{array}{c}110 \\
53.40 \%\end{array}$ & 1 & $\begin{array}{c}219 \\
51.05 \%\end{array}$ & 1 & $\begin{array}{c}4 \\
18.18 \%\end{array}$ & 3 & $\begin{array}{c}19 \\
61.29 \%\end{array}$ & 2 & $\begin{array}{c}23 \\
43.40 \%\end{array}$ & 2 \\
\hline Teaching & $\begin{array}{c}164 \\
65.60 \%\end{array}$ & 4 & $\begin{array}{c}141 \\
56.18 \%\end{array}$ & 2 & $\begin{array}{c}305 \\
60.88 \%\end{array}$ & 2 & $\begin{array}{c}108 \\
46.35 \%\end{array}$ & 2 & $\begin{array}{c}95 \\
46.12 \%\end{array}$ & 2 & $\begin{array}{c}203 \\
47.32 \%\end{array}$ & 2 & $\begin{array}{c}9 \\
40.90 \%\end{array}$ & 4 & $\begin{array}{c}11 \\
35.48 \%\end{array}$ & 3 & $\begin{array}{c}20 \\
37.74 \%\end{array}$ & 3 \\
\hline Learning & $\begin{array}{c}174 \\
69.60 \%\end{array}$ & 3 & $\begin{array}{c}64 \\
25.50 \%\end{array}$ & 4 & $\begin{array}{c}238 \\
47.50 \%\end{array}$ & 4 & $\begin{array}{c}61 \\
26.18 \%\end{array}$ & 4 & $\begin{array}{c}73 \\
35.44 \%\end{array}$ & 3 & $\begin{array}{c}134 \\
31.24 \%\end{array}$ & 4 & $\begin{array}{c}12 \\
54.55 \%\end{array}$ & 1 & $\begin{array}{c}4 \\
12.90 \%\end{array}$ & 5 & $\begin{array}{c}16 \\
30.19 \%\end{array}$ & 4 \\
\hline Teachers & $\begin{array}{c}229 \\
91.60 \%\end{array}$ & 2 & $\begin{array}{c}76 \\
30.28 \%\end{array}$ & 3 & $\begin{array}{c}305 \\
60.88 \%\end{array}$ & 2 & $\begin{array}{c}107 \\
45.92 \%\end{array}$ & 3 & $\begin{array}{c}63 \\
30.58 \%\end{array}$ & 4 & $\begin{array}{c}170 \\
39.63 \%\end{array}$ & 3 & $\begin{array}{c}8 \\
36.36 \%\end{array}$ & 2 & $\begin{array}{c}26 \\
83.87 \%\end{array}$ & 1 & $\begin{array}{c}34 \\
64.15 \%\end{array}$ & 1 \\
\hline Sc \& Ed & $\begin{array}{c}66 \\
26.40 \%\end{array}$ & 5 & $\begin{array}{c}39 \\
15.54 \%\end{array}$ & 5 & $\begin{array}{c}105 \\
20.96 \%\end{array}$ & 5 & $\begin{array}{c}46 \\
19.74 \%\end{array}$ & 5 & $\begin{array}{c}48 \\
23.30 \%\end{array}$ & 5 & $\begin{array}{c}94 \\
21.91 \%\end{array}$ & 5 & $\begin{array}{c}2 \\
9.09 \%\end{array}$ & 5 & $\begin{array}{c}6 \\
19.35 \%\end{array}$ & 4 & $\begin{array}{c}8 \\
15.09 \%\end{array}$ & 5 \\
\hline Total & \multicolumn{2}{|c|}{250} & \multicolumn{2}{|c|}{251} & \multicolumn{2}{|c|}{501} & \multicolumn{2}{|c|}{233} & \multicolumn{2}{|c|}{206} & \multicolumn{2}{|c|}{439} & \multicolumn{4}{|c|}{31} & \multicolumn{2}{|c|}{53} \\
\hline Category & \multicolumn{6}{|c|}{ IJSE $^{5}$} & \multicolumn{6}{|c|}{ RiSE $^{6}$} & \multicolumn{6}{|c|}{ Total } \\
\hline & $A^{7}$ & $R^{9}$ & $\mathbf{B}^{8}$ & $R^{9}$ & Total & $R^{9}$ & $A^{7}$ & $R^{9}$ & $\mathbf{B}^{8}$ & $R^{9}$ & Total & $R^{9}$ & 2005-9 & $R^{9}$ & 2010-4 & $R^{9}$ & Total & $R^{9}$ \\
\hline $\begin{array}{l}\text { Type: } \\
\text { Method }\end{array}$ & $\begin{array}{l}29910 \\
99.67 \%\end{array}$ & 1 & $\begin{array}{c}224 \\
38.82 \%\end{array}$ & 3 & $\begin{array}{c}523 \\
59.64 \%\end{array}$ & 2 & $\begin{array}{c}150 \\
100 \%\end{array}$ & 1 & $\begin{array}{c}86 \\
31.39 \%\end{array}$ & 3 & $\begin{array}{c}236 \\
55.53 \%\end{array}$ & 2 & $\begin{array}{c}944 \\
98.85 \%\end{array}$ & 1 & $\begin{array}{c}756 \\
65.46 \%\end{array}$ & 2 & $\begin{array}{c}1700 \\
74.10 \%\end{array}$ & 1 \\
\hline Level & $\begin{array}{c}87 \\
29.00 \%\end{array}$ & 3 & $\begin{array}{c}446 \\
77.30 \%\end{array}$ & 1 & $\begin{array}{c}533 \\
60.78 \%\end{array}$ & 1 & $\begin{array}{c}101 \\
67.33 \%\end{array}$ & 2 & $\begin{array}{c}207 \\
75.55 \%\end{array}$ & 1 & $\begin{array}{c}308 \\
72.47 \%\end{array}$ & 1 & $\begin{array}{c}560 \\
58.64 \%\end{array}$ & 2 & $\begin{array}{c}991 \\
74.01 \%\end{array}$ & 1 & $\begin{array}{c}1551 \\
67.61 \%\end{array}$ & 2 \\
\hline Discipline & $\begin{array}{c}106 \\
35.33 \%\end{array}$ & 2 & $\begin{array}{c}279 \\
48.35 \%\end{array}$ & 2 & $\begin{array}{c}385 \\
43.90 \%\end{array}$ & 3 & $\begin{array}{c}59 \\
39.33 \%\end{array}$ & 3 & $\begin{array}{c}140 \\
51.09 \%\end{array}$ & 2 & $\begin{array}{c}199 \\
46.82 \%\end{array}$ & 3 & $\begin{array}{c}377 \\
35.29 \%\end{array}$ & 3 & $\begin{array}{c}594 \\
44.36 \%\end{array}$ & 3 & $\begin{array}{c}931 \\
46.58 \%\end{array}$ & 3 \\
\hline $\begin{array}{c}\text { Topic: } \\
\text { ScLiteracy }\end{array}$ & $\begin{array}{c}112 \\
37.33 \%\end{array}$ & 3 & $\begin{array}{c}120 \\
20.80 \%\end{array}$ & 3 & $\begin{array}{c}232 \\
26.45 \%\end{array}$ & 3 & $\begin{array}{c}55 \\
36.67 \%\end{array}$ & 3 & $\begin{array}{c}59 \\
21.53 \%\end{array}$ & 3 & $\begin{array}{c}114 \\
26.82 \%\end{array}$ & 4 & $\begin{array}{c}522 \\
54.66 \%\end{array}$ & 3 & $\begin{array}{c}669 \\
49.96 \%\end{array}$ & 1 & $\begin{array}{c}1191 \\
51.92 \%\end{array}$ & 1 \\
\hline Teaching & $\begin{array}{c}136 \\
45.33 \%\end{array}$ & 2 & $\begin{array}{c}219 \\
37.95 \%\end{array}$ & 1 & $\begin{array}{c}355 \\
40.48 \%\end{array}$ & 2 & $\begin{array}{c}51 \\
34.00 \%\end{array}$ & 4 & $\begin{array}{c}101 \\
36.86 \%\end{array}$ & 1 & $\begin{array}{c}152 \\
35.76 \%\end{array}$ & 2 & $\begin{array}{c}468 \\
49.00 \%\end{array}$ & 4 & $\begin{array}{c}567 \\
42.35 \%\end{array}$ & 2 & $\begin{array}{c}1035 \\
45.12 \%\end{array}$ & 2 \\
\hline Learning & $\begin{array}{c}240 \\
80.00 \%\end{array}$ & 1 & $\begin{array}{c}187 \\
32.41 \%\end{array}$ & 2 & $\begin{array}{c}427 \\
48.69 \%\end{array}$ & 1 & $\begin{array}{c}91 \\
60.67 \%\end{array}$ & 1 & $\begin{array}{c}65 \\
23.72 \%\end{array}$ & 2 & $\begin{array}{c}156 \\
36.71 \%\end{array}$ & 1 & $\begin{array}{c}578 \\
60.52 \%\end{array}$ & 1 & $\begin{array}{c}393 \\
29.35 \%\end{array}$ & 3 & $\begin{array}{c}971 \\
42.33 \%\end{array}$ & 3 \\
\hline Teachers & $\begin{array}{c}107 \\
35.67 \%\end{array}$ & 4 & $\begin{array}{c}94 \\
16.29 \%\end{array}$ & 4 & $\begin{array}{c}201 \\
22.92 \%\end{array}$ & 4 & $\begin{array}{c}66 \\
44.00 \%\end{array}$ & 2 & $\begin{array}{c}50 \\
18.25 \%\end{array}$ & 4 & $\begin{array}{c}116 \\
27.29 \%\end{array}$ & 3 & $\begin{array}{c}574 \\
57.28 \%\end{array}$ & 2 & $\begin{array}{c}309 \\
23.08 \%\end{array}$ & 4 & $\begin{array}{c}883 \\
38.49 \%\end{array}$ & 4 \\
\hline
\end{tabular}


Table 1. Cont

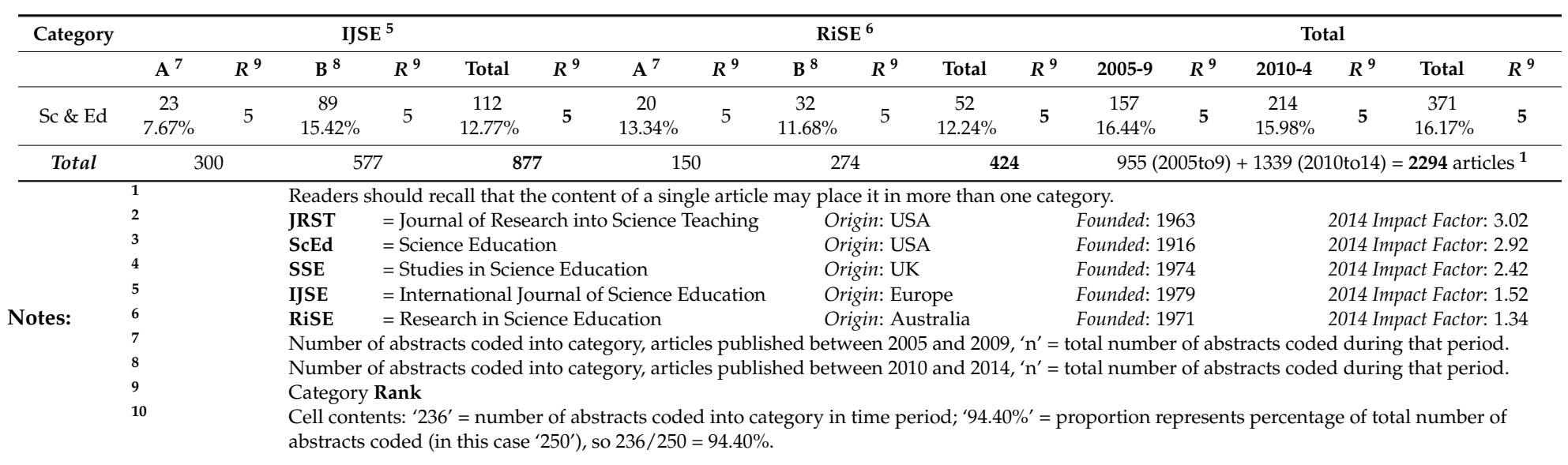




\section{Results}

The results of the application of the analysis category framework to these five journals appear in Table 1 Broad coding categories by Journal. The 'Notes' to Table 1 provide details of each journal; including impact factors at the end of the review period, which were sourced from journal web pages. The difference between distributions of broad codes for articles published between 2005 and 2009 and those published between 2010 and 2014 was statistically significant (Sig $=0.005 ; p<0.01$ ) across the five journals, reported Effect Size was large (Partial Eta Squared $=0.556 ; \eta^{2}>0.138$ ) and Power was high (Observed Power $=0.953$ ).

Both statistical significance and effect size are adequate and power exceeds the desired 0.8 criterion. The differences for individual journals were also statistically significant $(p<0.05$ in all cases), with adequate effect size ( $\eta^{2}>0.138$ in all cases) and observed power ranging from 0.5 to 0.9. The differences between counts presented in Table 1 are robust enough to permit subsequent discussion, some of which will draw on sub-category data (see Appendixs B and C) to illuminate issues raised by the broad analysis.

\subsection{Publication Changes: 2005 to 2014}

It is apparent from Table 1 that the number of substantive articles published by these five research journals has increased over the decade in question (with a 17\% rise between the first and second half of the period, mainly attributable to $50 \%$ increases in numbers of articles published by IJSE and RiSE). This makes ranks and proportional measures more useful for comparison of trends than absolute numbers of publications in a particular category.

Readers should recall that coding placed abstracts in more than one sub-category if their content warranted it. For example, consider the total proportions for publication by topic for Journal of Research in Science Teaching (JRST): around 82\% of abstracts were coded as involving scientific literacy (Rank: 1) and around 48\% were coded as involving learning (Rank: 4). This yields a total that is manifestly greater than $100 \%$ because reviewers coded single abstracts into more than one sub-category.

\subsection{Types of Research}

The 'Type' category coded the method applied during the research being reported, the educational level at which the research was focused and the science discipline that formed the context for the study. Subsequent discussion will draw on the sub-categories within these broad areas across the five surveyed journals, the data for which appears as Appendix B.

\subsubsection{Research Method}

Almost three-quarters of the abstracts $(1700 / 2294=74.11 \%$ from 2005 to 2014$)$ specified detail that allowed them to be sorted by research methodology. Abstracts from Journal of Research into Science Teaching (JRST) and Science Education (ScEd) specify approach more often, with $90 \%$ of coded abstracts specifying Method, across both five-year spans. The expectations of International Journal of Science Education (IJSE) and Research in Science Education (RiSE) editors seem less consistent, with such specification dropping in the second span to leave an overall proportion between 55\% and $60 \%$. Consequently, overall proportions drop from $98.85 \%$ to $65.46 \%$, leaving a ten-year span proportion of $74.1 \%$.

Tsai and co-workers [8] earlier coded some papers as Empirical and such papers form the highest proportion of publications whose abstracts allowed identification of research method between 2005 and 2014 (56\%). However, Position papers gained proportional share (rising from 7\% to 13\%) as the total number of papers published grew during the second part of the decade, while papers identified as Empirical formed a lesser proportion (dropping from $84 \%$ to $37 \%$ across the ten period).

Within that 'Empirical' group, Qualitative methodologies (at 32\% across the ten-year span) are twice as common as Quantitative approaches (at 15\%), and Mixed methods (at 9\%) appear less common 
than might have been supposed. The declining identification of research methodologies noted prompts caution in interpreting these trends but they remain interesting nonetheless. The findings of this survey do not support an expectation that quantitative methods would dominate Science Education research and that editors will be inevitably suspicious of more qualitative approaches. In fact, there is a clear drop in researcher specificity regarding methodology ( $47 \%$ drop between the 5 -year spans) and, while the proportional ranks remained steady, the actual percentages of abstracts which could be coded as explicitly quantitative (almost $15 \%$ across the ten years) dropped from $23 \%$ to $9 \%$ between the five-year spans (2005 to 2009 and 2010 to 2014). The complex nature of Science Education may lead some to see a natural fit with mixed methods but that is not evident either. Various combinations of comparative and descriptive approaches accounted for just under ten percent of coded abstracts (falling from 13\% to $6 \%$ across the spans).

The position of Theoretical and Review work seems to have been low ( $2 \%$ and $5 \%$, respectively) but relatively stable across this ten-year span. Almost half of the review articles came from SSE, which is unsurprising given the nature of that journal.

\subsubsection{Educational Level}

The patterns for specification of Level differ, with JRST and ScEd dropping by around $10 \%$ each between the five-year spans and the proportion of abstracts that specify educational level rising in both IJSE and RISE, quite substantially in the case of the former journal.

Most of the abstracts that specify an educational level in these journals deal with Secondary schooling and the proportion has apparently risen, from just under a third to just over a third of the published articles. There is consistent, if somewhat meagre, interest in science at the Early Childhood level (around 2\% of identifiable abstracts) and greater, if still minor, interest in Primary school science $(17 \%)$. There seems to be a positive trend in concern for Post-secondary science education across the decade (from $13 \%$ to $21 \%$ ) displacing a focus on primary schools from second rank in the latter half of the ten-year span.

\subsubsection{Discipline Context}

Scientific discipline is specified in around half of these abstracts across the ten-year span. The specification of discipline context varies between the journals, with ScEd dropping by about $10 \%$, SSE by about $6 \%$, RiSE by about $3 \%$ and JRST dropping by about $2 \%$, while IJSE rose by about $13 \%$.

Just under half of the articles published in these five journals had an explicit discipline base, across the ten-year span, with Physics (coded to include Astronomy and Astrophysics) as of consistently greatest interest (14\%), closely followed by Biology (at 13\%) and then Chemistry (at 10\%). Papers dealing with Geology (at 2\%) and Environmental \& Marine Science (at 4\%) were published considerably less often although the latter disciplines appeared more often in the second five-year span (from 20 papers and $2 \%$ of identifiable abstracts to 77 papers and $6 \%$ ).

The inclusion of Astronomy papers in the Physics category, rather than with Geology ('Earth Space Science' being a 'teachable' in some jurisdictions) may appear a problematic decision but it would have made little difference, as there were only eight Astronomy articles published between 2005 and 2009 and only five between 2010 and 2014, the bulk of which were in IJSE. Similarly, the separation of Environmental and Marine Science from Geology may raise questions but the collapse of those two sub-categories would still place the combination at lowest rank.

\subsection{Topics for Research}

'Topic' refers to the area of Science Education that provided the research questions for the work in question. An initial list of topics emerged from the first pragmatic analysis and this was refined and enlarged through the later iterations of the survey. Emergent topics initiated re-analysis of existing data.

The final broad topics were scientific literacy in its various manifestations; the things that science teachers do; the ways that students learn; how teachers prepare to teach and maintain their currency 
within their profession; and the interactions between science teachers and the scientists and science that provide the content that they share with their students.

\subsubsection{Scientific Literacy}

Scientific Literacy represents a contested area of considerable interest. It deals not so much with issues of learning as with issues of curriculum: what should be learnt and by whom? The category has the highest publication rank for JRST and ScEd but seems less important for SSE, IJSE and RiSE, ranking second, third and fourth respectively.

Application issues (including 'Public Understanding of Science') seem less apparent than might have been expected and of apparently declining interest (negative trend from $11 \%$ to $4 \%$ across the decade). Concern for Access in science seems strong (initially coded as 'Communication': maintaining highest rank across the ten-year span, with a drop from 25\% to 22\%) and Engagement seems of rising interest between 2005 and 2014 (from 19\% to 24\% between the five-year spans). Reference to the coding details preserved in Appendix A will clarify the distinction between these sub-categories.

\subsubsection{Teaching}

Teaching is of understandably enduring interest. How do, and/or should, science teachers act in class? The category ranked second, across the ten-year span, for JRST, ScEd, IJSE \& RiSE, and third for SSE.

Teaching Strategies maintain a high level of interest with a slight downward trend in the second part of the decade (from 19\% to 15\%), while specific treatment of Practical Work maintains a steady level of publication (at around 8\% to 9\%). ICT and Assessment are also of consistent, though lesser, interest in these journals (both at around $7 \%$ of identifiable abstracts).

\subsubsection{Learning}

Learning is central to the work of science teachers and therefore it is not surprising that articles dealing with it should find a place in journals such as those surveyed here. It is the most highly ranked topic across the decade for RiSE (37\% of abstracts, trending down on overall proportion) and IJSE (49\%, also trending down on overall proportion). The category ranks much lower for JRST and ScEd but the overall proportion of abstracts so coded is not dissimilar: both rank 'Learning' at 4th but the abstracts coded represent $48 \%$, (trending down on overall proportion) and $31 \%$ (trending up on overall proportion) of the ten-year totals, respectively.

Learning theories in general (including self-efficacy, metacognition, developmentalism, and instrumentalism) seem to be of declining interest, accounting for almost $14 \%$ of publications during the first part of the decade but only $4 \%$ in the second.

Although Constructivism remains the largest sub-category within 'Learning', its trend is remarkably negative (from $30 \%$ of abstract-identifiable publications in the first half of the decade to $13 \%$ in the second, with an absolute drop of 116 coded abstracts). Work continues on distinguishing between teacher and student Interactions, examining Student Reasoning and the nature of Student Conceptions about particular science content. Attitudes, in general and based on student grade and gender, are another minor focus of published research into learning in these five journals.

\subsubsection{Teachers}

Teachers are the link between teaching and learning and so it is reasonable that articles dealing with their preparation and continued roles and development should make up around a third of the articles published in these five journals, with the top rank for SSE and a moderate ranking for the other journals.

There seems to be a downward trend in all of the elements that make up the Teacher category, including Preparation of Teachers and Professional Development within the context of increasing numbers of articles overall. The drop in publications concerned with Curriculum change (from $11 \%$ 
to $4 \%$ ) may represent a settling of the millennial flurry of policy change but the drop in publications concerning Pedagogical Content Knowledge ( $12 \%$ of abstracts coded across the decade, dropping from $16 \%$ to $4 \%$ between the five-year spans) warrants further discussion.

\subsubsection{Relations between Science and Education}

Relations between Science and Education seem to be of minor but consistent and enduring interest, maintaining a low but consistent level of publication across the decade. The History and Nature of Science remains of interest (at around $11 \%$ of identifiable abstracts), including modelling, methods, cultural influences and connections with learning difficulties. Concern for the Relationship between Science and Education may form an emerging issue with high school students doing science internships, directly interacting with scientists; dealing with the work of scientists, and exploring factors that encourage scientific careers (at around $5 \%$ ).

The pattern of topics reviewed in SSE reveals a greater level of interest in some things that were less prominent in the other four journals. For example, although abstracts dealing with Physics rank as highly in SSE as they do when the other four journals are aggregated, the less prominent Earth Space sciences were surveyed in four separate articles across the decade, which represents noticeable focus among the fewer articles published by SSE. Conversely, there were 23 surveys of issues connected with Scientific Literacy during the same period, supporting the strength of interest in research within that area apparent in some of the other journals. In common with them, the SSE surveys dealt substantially with Communication issues, with 12 such articles across the decade. There was more activity in the first five-year span, so the time might be ripe for more work in this area. Teacher preparation and work was relatively more visible among these survey articles than it was in the other four journals.

\section{Discussion}

Abstracts have a number of forms across research literature. The differences represent different researcher (and editor) perceptions of the function of the abstract and these perceptions appear to vary with researcher origin and disciplinary target [22]. Some authors write abstracts to motivate readers to read the complete article, while others provide a succinct summary of the main findings of the study, reflecting the structure of the paper as a whole and presenting its substance as assertions for which the detail appears in the article itself. The vast majority of the abstracts analyzed in this study were of that more structured variety. This is unsurprising, given that the formal scientific report is the conventional format with which these researchers would presumably be most familiar. More surprisingly, this survey suggests that the abstracts in these journals became less informative, and possibly more motivational, across the ten years in question.

The data on Research Methodology also reflects a somewhat unexpected pattern, with qualitative research appearing more common than quantitative. Science education often sits within tertiary Schools of Education, rather than Science, and those of us working in that field have become accustomed to the expectation that we will fall on one side of the methodology wars $[23,24]$, although our community has long exhibited sensitivity to the importance of methodological diversity [25]. There has been a recent surge in the preference for quantitative work [4] but these journals appear to have been quite receptive to a range of methodologies across the ten years in question. Abstracts were more precise in Journal of Research into Science Teaching (JRST) and Science Education (ScEd), with quantitative and qualitative papers being of roughly equal proportions for ScEd while qualitative methods were apparently three times as common as quantitative in JRST.

Research concerning science education in Early Childhood seems scant in these journals. This may be because of the presence of numerous specialist journals for Early Childhood but the practical nature of scientific investigation and the wide variety of experiences that it offers makes $2 \%$ of articles published in journals such as these a surprisingly low proportion.

The linked disciplines of Space, Earth, Marine and Environmental Science did not receive the attention in these journals that might have been expected, given the interest that students often exhibit 
in these fields and their presence in popular media. Again, this may be partly due to the existence of excellent specialist journals but is noteworthy nonetheless. The relatively low publication rate for Environmental and Marine Sciences (four papers a year for the first half and 15 per year for the second) may represent a research opportunity, rather than lack of interest.

The understandable focus on Secondary Schooling need not have led to the apparent neglect of Informal Science Education. Excursions are commonly a valued part of school science programs and established venues are highly attractive in increasingly safety-conscious times; and so it seems strange that less that ten percent of the articles published in these journals report research into their more effective use. This may be another instance of the impact of more specific journals.

A generational shift may be visible in the results of the present survey. Pedagogical Content Knowledge seems to have been diminishing as an area of publication, as are Constructivism and the Public Understanding of Science. Each of these has provided a direction for research in science education across past decades. It is unclear whether we are looking at declining work because of declining interest in a field whose research potential appears exhausted or at a generational change in researchers. However, there are conceptual links between the three topics and their common decline in the second five-year span is interesting.

The data produced by this survey reflects publication patterns and the language used to describe them has shifted between 'interest' and 'activity'. More publication may reflect greater interest, rather than greater activity and less publication may reflect less activity rather than less interest, or be an indication of editorial interest. However, it is likely that topics trending upwards between the two halves of the decade in question may represent an emerging research gap and that, conversely, a downward trend represents a less fertile section of our field.

\section{Comparison with Previous Reviews of the Field}

Direct comparison of the reviews is difficult because of the differences between journals surveyed, time spans and coding categories reported, but some comment is possible.

Choice of journal has an obvious impact on the results of any publication survey. Both this review and the work of the Tsai group $[8,10,11]$ report a growing number of articles in the three journals common to the two surveys (JRST, ScEd and IJSE). The earlier reviews report an increase of 188 articles (1998 to 2012), while the present work reveals a growth of 251 articles in the same three journals (2005 to 2014). The growth in publications seems to have accelerated. The proportions of articles coded as 'Learning' appear broadly similar, with both reviews suggesting that ScEd publishes less in this area than JRST or IJSE. In the same way, the proportions for articles dealing with 'Science \& Education' seem of the lowest ranked importance in these journals across the different time spans, with the proportion of such articles increasing as time passes and with IJSE seeming proportionally less interested. There does seem to be a measure of agreement between the two accounts, notwithstanding the differences between the backgrounds to the two reviews. The present work expands the journal reach by including analysis of RiSE and SSE.

Choice of classification framework has a similarly obvious impact on analysis outcomes. The earlier work [11] reports research types under four headings, based on previous classification of educational psychology publications (Empirical, Position, Theory, Review and Other). They report research topics under seven headings, based on strands within the National Association for Research in Science Teaching conference (Teacher education; Teaching; Learning-conception; Learning-context; Goals, purpose and curriculum; Philosophy, history and NOS; Educational technology; and Informal learning). There is no doubting the convenience of categories from such sources but, once chosen, they set limits on the information that analysis may produce. Our coding categories emerged from the iterative nature of the present review: three categories for research type (Method, Level and Discipline) and five for research topic (Scientific Literacy, Teaching, Learning, Teachers and Science \& Education). More fine-grained use of various levels of sub-category clarified the categories that we adopted (see Appendix B). For example, an early, parallel review of 'English for Specific Purposes' and 'Journal 
of English for Academic Purposes' by the third author suggested the more specific coding of the 'Empirical' sub-category into 'Quantitative' and 'Qualitative' and 'Mixed Method' research. This allows the present analysis to speak directly to contested issues of methodology in a way that earlier, coarser categorization could not. Further, readers will recall that 'Empirical' papers formed the highest proportion of publications across our ten-year span but this proportion dropped in the second five-year span as 'Position' papers gained proportional share. This trend does not reflect that noted by the Tsai group in the smaller group of journals that they surveyed: $86.9 \%$ 'empirical' vs. $9.4 \%$ 'position' (1998-2002), $87.8 \%$ vs. $4.1 \%$ (2003-2007) and $90.7 \%$ vs. $2.6 \%$ (2008-2012). The present paper has already drawn attention to the differences between JRST \& IJSE, on the one hand, and ScEd \& RiSE, on the other. The final paper in the Tsai series contains a comparative table across the 15 years that their project ran that also shows a consistently lower proportion of empirical papers in ScEd [11]. This may explain the apparent difference in the findings of the reviews and provide some confidence in the results of the more fine-grained analysis presented in previous sections of this paper.

Coding decisions similarly establish both possibilities and limitations for later analysis. We multiple-coded single articles if their content reflected more than one sub-category, in contrast to previous work which had "categorized each sample paper into one, single best-fit category" [11]. Our looser coding preserved comparative content data that would otherwise have been lost in addition to reducing the impact of variation in reviewer perceptions.

The specific issue of 'Constructivism' may provide a useful lens through which to view the relative contributions of the present and earlier reviews. Both of the earlier, automated reviews indicated high interest in the interaction of student prior knowledge and subsequent learning, either reporting it as the most published issue (across a 17-year span for Reference 2) or identifying it as a central component of scientific inquiry (across a 24-year span for Reference 3). More traditional reviews support this, while recognising early signs of declining interest/activity [8] in what is commonly called 'constructivism' and its later displacement from pride of place [10]. This declining importance also appears in the results of the present survey, where the 'Learning' category slips from first rank across the five journals (2005-2009) to third (2010-2014), with its 'Constructivism' sub-category slipping from $30 \%$ to $13 \%$ of coded abstracts.

It may be that we are looking at a contemporary example of "the dubious privilege of each new wave of learning theorists to rewrite the history of how science used to be taught to suit their own, current, agenda" [19]. However, other, more general 'Learning Theories' also seem to be diminishing in output (10\% across the decade, dropping from $14 \%$ to $4 \%$ ). Changing editorial views of constructivist research are becoming explicit:

"JRST readers and reviewers now expect the documentation of some nave conceptions to serve as only the first step in a research effort, to be complemented in the same study with a theoretically-informed intervention to meaningfully address those conceptions." [26]

The use of automated tools will inevitably encourage the analysis of large datasets covering work across many years and the exigencies of publication encourage the collapse of categories into headings that are apparently easy to understand. These two pressures may act together to produce large, relatively coarse analyses that miss more fine-grained changes, such as the diminishing status of 'Constructivism' within Science Education that is revealed by the present analysis.

\section{An Example of Use}

This survey appears in a Special Issue on "Interactive Simulations and Innovative Pedagogy for Conceptual Understanding in Science Education". This title suggests concern for the creative use of ICT as one tool for the encouragement of conceptual change in science students. This Special Issue provides a timely opportunity to challenge an example of the 'drill down' approach to reviewing literature in an authentic publication context. 
How current were the concerns of this Special Issue in these journals that sit at the centre of their research field? Which journals might be most helpful in ascertaining the contemporary state of play within that mainstream? Which journals might be more interested in publishing the results of subsequent work? Such questions would interest people long resident in this part of the research field and people considering immigration or colonization. Answering these questions requires dipping into the data provided in this paper a number of times, increasing depth.

Appendix A places 'strategies' and 'ICT' in the Topic 'Teaching' and places 'Conceptual Change' within the sub-topic 'Constructivism', in the Topic 'Learning'.

Table 1 shows that 'Teaching' and 'Learning' rank second and third, respectively, within these five research journals across that ten years. There should be quite a lot of work available to interested researchers from these five journals. The former increased in publication rank (from fourth to second) between the five-year spans but the latter dropped from first to third. 'ICT' and 'strategies' may draw on more recently published resources and may find a more receptive audience than 'conceptual change' but we need to dig a little deeper. 'Teaching' appears to be a focus for RiSE (ranking first in the later five-year span) and 'Learning' ranks first across the ten years and second during the later five-year span. The same pattern appears when we shift to the left on Table 1 and consider IJSE. However, 'Teaching' ranks consistently second for ScEd but 'Learning' is less visible in that journal: ranking fourth overall and only rising from fourth to third between the five-year spans. 'Learning' also seems relatively neglected in JRST (overall ranking fourth) but 'Teaching' ranks second, with a lift from fourth to second between the five-year spans.

Therefore, this analysis suggests that those concerned with 'ICT' or 'strategies' should scan all five journals for articles of particular interest to them. A focus on 'Conceptual Change' would make RiSE and IJSE more likely to be useful. These topics are less visible in SSE (Table 1) but the nature of that journal means that it may reward a closer look-a single review article covering any area of particular research interest is going to tell you more than topic rank order. However, all of this represents a fairly coarse analysis.

Appendix B indicates that 'strategies' in general were the most frequent of the 'Teaching' sub-topics, with ICT lifting from fourth rank to third, and 'Constructivism' was consistently the most frequent topic for publications within 'Learning', notwithstanding the overall drop in publication mentioned previously. Appendix $C$ dips deeper into the basic data, with a specific focus on constructivism. It emerges that articles dealing with 'Constructivism' formed a larger proportion of publications dealing with 'Learning' in IJSE in the second 5-year span (rising from $43 \%$ to $53 \%$ of 'Learning' articles) but that those dealing with conceptual change dropped from $22 \%$ to $4 \%$ of these. There were 27 articles dealing with conceptual change in IJSE between 2005 and 2014. The same trend is visible in RiSE, although a greater proportion of articles dealt with these issues between 2005 and 2009. The Australian origin of the latter journal has been mentioned previously and conceptual change seems to have been a special focus for researchers in that part of the world in the time leading up to that covered by this survey [27]. The data presented on Appendix C supports the identification of these journals if the focus of work is to be the impact of ICT-based simulation on conceptual change, while suggesting that JRST might also be a useful source of work published during the first five-year span, notwithstanding the proportionally fewer publications within 'Learning' in general within that journal.

\section{Conclusions and Implications}

The previous section indicates that the abstract-based, drill-down approach to reviews adopted in this work provides a useful illumination of this field.

There is apparent diversity in the form and function of the abstracts in these journals. Journal of Research in Science Teaching (JRST) and International Journal of Science Education (IJSE) tend to have greater specificity than Science Education ( $\mathrm{ScEd}$ ) and Research in Science Education (RiSE) but 
all journals appear to have accepted less structured abstracts in the second five-year span than they did in the first. The usefulness of various formats for research abstracts may well reward further work.

Secondary schooling appeared to be the most published level for all of the journals surveyed, with JRST and IJSE publishing more work at the lower ranking post-secondary level and ScEd and RiSE seemingly more interested in primary classrooms. This may guide researchers who are looking for outlets for their work at these levels.

Papers dealing with Biology were more common in JRST but Physics was a more common disciplinary foundation for research in the other journals. Scientific literacy is the most common topic in JRST and ScEd but less common in IJSE and RiSE, where Learning takes pride of place. Scientific literacy moved up in publication rank, as did Teaching, while Learning and Teachers diminished in relative importance amid the changing patterns of publication. The relations between Science and Education maintained a consistent, if lower, level of interest with JRST and ScEd maintaining the highest proportional level of interest. Such data may be useful to novice researchers who are beginning work in these areas.

The research surveyed in this review reveals influences from both of Snow's 'Two Cultures' [1] and like many other border regions it reveals variations of pressure in both time and space. Many of these researchers initially trained within science traditions that focus on comparison and measurement, which inclines them to quantitative work; while the messy educational context in which they find themselves produces a heightened awareness of the importance of the particular, of the irreducibility of classroom complexity, of the necessity for illumination of obscure experiences and connections [28]. We sometimes work under pressure to "examine our own practices and see on which side we stand" but this should be resisted [29]. The pattern of research methods revealed by this survey suggests that quantitative and qualitative approaches may not be as incommensurable as enthusiasts sometimes claim but the relative lack of mixed methods suggests that those same enthusiasts are still exercising considerable influence. All methodologies seem welcome in these journals and the preponderance of qualitative studies may be unexpected. Mixed Methods, which makes explanation more plausible by combining rich description with comparison of measurements, appears less common than might be expected but this provides an opportunity for researchers who wish to apply this approach to the complexities of the field. Such indication of flexibility should be tempered by contemporary concerns for "study designs not conducive to quantitative synthesis, ... limitations resulting from (incomplete) reporting practices and ... lack of replications of intervention studies" [4]. Rigour may look different under different methodologies but it is necessary nonetheless. Comparison of the methodological contents of abstracts and the full articles that they purport to introduce may illuminate the connections between them and challenge the appearance of diversity described in this paper.

The decision to focus on the research terrain and leave aside the border region between research in science education and its application in school and beyond accompanied widening this review beyond its original, parochial focus. We regret the necessity of this decision and see a clear need to move beyond 'What's hot in science education research?' to 'What meals are made from the heated ingredients?' The interaction between research and practice, as indicated by comparison between journals such those reviewed here and practitioner journals at informal, school and university levels is a separate but very important question. Some such work has been published and a complex form of the ubiquitous research/practice conundrum emerged when the interface between science education and language issues was examined [24].

This study opens up a number of questions that would reward subsequent, deeper analysis of themes that emerged from it. The form and function of variations in the abstract would reward deeper investigation. Explicit comparison of the impact of the different approaches to reviews is the subject of on-going work. The issues of decline in publication dealing with learning theories and the four-fold drop in interest in Pedagogical Content Knowledge also seem to be of potential interest. The data set on which this paper was based would allow the development and challenge of more effective 
models in areas such as scientific literacy. This analysis also leaves open the question of the best way to describe and represent shifting patterns of interest within particular topic areas.

Author Contributions: The first author produced a pragmatic five-year review of local science educator and teacher journals, subsequently co-ordinated the work and did the bulk of the writing. The third author expanded journal coverage, which the fourth subsequently continued before the second author expanded and substantially re-worked the coding.

Acknowledgments: This project was carried out without external funding.

Conflicts of Interest: The authors declare no conflict of interest.

\section{Appendix A. Analysis Category Sheet}

Type

Research Method:

Level of Schooling:

Discipline Context:

Topic

Scientific Literacy:

Teaching

\section{Journal: $\underline{\mathbf{X X X X}}$}

Quantitative research, either quasi-experimental $\mathrm{xxxx}$, correlational $\mathrm{xxxx}$, survey-based $\mathrm{xxxx}$ or evaluative $\mathrm{xxxx}$ that attempts to compare two or more things. Qualitative research $\mathrm{xxxx}$, either document analysis $\mathrm{xxxx}$, case study $\mathrm{xxxx}$, narrative $\mathrm{xxxx}$, or ethnography (field notes, survey and interview), $\mathrm{xxxx}$ that attempts to accurately describe.

Mixed Method xxxx that use qual. methods to give meaning to quant. comparisons.

Position Papers xxxx that try to open up issues through clear statement of particular views.

Theoretical Papers xxxx that exemplify broader models or approaches, such as critical theory $\mathrm{xxxx}$ or economic rationalism $\mathrm{xxxx}$ or novel methodologies $\mathrm{xxxx}$. Review articles xxxx that summarise research literature in Science Education. Early Childhood xxxx

Primary, K-6 xxxx, including middle school references $\mathrm{xxxx}$ Secondary 7-10 xxxx, including middle school references $\mathrm{xxxx}$ Post-secondary including university $\mathrm{xxxx}$, and technical contexts $\mathrm{xxx \textrm {x }}$ Physics $\mathrm{xxxx}$, Chemistry $\mathrm{xxxx}$

Biology $\mathrm{xxxx}$

Geology $\mathrm{xxxx}$

Environmental \& Marine Science xxxx

Access, both spoken and written xxxx; dealing with use of actual scientific papers (or other authentic science literature) $\mathrm{xxxx}$, diagrams $\mathrm{xxxx}$, the impact of bilingualism $\mathrm{xxxx}$, some focus on argumentation $\mathrm{xxxx}$ and explanation $\mathrm{xxxx}$ Application of science $\mathrm{xxxx}$ metaphoric use of 'literacy' persists

Engagement: $\mathrm{xxxx}$, informal learning $\mathrm{xxxx}$, museums and zoos $\mathrm{xxxx}$, science centres $\mathrm{xxxx}$, field work $\mathrm{xxxx}$, SocioScientific issues $\mathrm{xxxx}$ including genetics $\mathrm{xxxx}$, global warming $\mathrm{xxxx}$, biodiversity $\mathrm{xxxx}$, science/religion $\mathrm{xxxx}$, cloning $\mathrm{xxxx}$ and how to deal with them $\mathrm{xxxx}$, SocioCultural issues $\mathrm{xxxx}$ that specifically recognise the impact of different learner $\mathrm{xxxx}$, or teacher $\mathrm{xxxx}$, cultures.

Strategies: PBL $\mathrm{xxxx}$, as opposed to problem solving $\mathrm{xxxx}$, group work $\mathrm{xxxx}$, discussions $\mathrm{xxxx}$, co-operative learning (jigsaw) $\mathrm{xxxx}$, student perceptions of effectiveness $\mathrm{xxxx}$

Practical Work xxxx involving balance between substantive and procedural knowledge $\mathrm{xxxx}$, approaches to assessment $\mathrm{xxxx}$, authentic $\mathrm{xxxx}$, as inquiry $\mathrm{xxxx}$ ICT seems to be becoming mainstream $\mathrm{xxxx}$ : animation $\mathrm{xxxx}$, concept mapping $\mathrm{xxxx}$, flow charting $\mathrm{xxxx}$, video prompts $\mathrm{xxxx}$ and evaluations of its effectiveness $\mathrm{xxxx}$

Assessment $\mathrm{xxxx}$ self efficacy $\mathrm{xxxx}$, metacognition $\mathrm{xxxx}$, developmentalism $\mathrm{xxxx}$, instrumentalism $\mathrm{xxxx}$ 
Learning

Teachers

Relations between Science \& Education
Theories $\mathrm{xxxx}$ self efficacy $\mathrm{xxxx}$, metacognition $\mathrm{xxxx}$, developmentalism $\mathrm{xxxx}$, instrumentalism $\mathrm{xxxx}$

Constructivism $\mathrm{xxxx}$ seems to be moving to pedagogical/conceptual change $\mathrm{xxxx}$ rather than the radical direction $\mathrm{xxxx}$, distinguishing between teacher and student interactions $\mathrm{xxxx}$, examining student reasoning $\mathrm{xxxx}$, while still maintaining an interest in nature of student conceptions $\mathrm{xxxx}$ about particular issues of content. Attitudes xxxx based on grade $\mathrm{xxxx}$ and gender $\mathrm{xxxx}$

Training in various forms $\mathrm{xxxx}$, developing professionalism $\mathrm{xxxx}$, practicum experience $\mathrm{xxxx}$, changing attitudes $\mathrm{xxxx}$, induction/innovation $\mathrm{xxxx}$, on-going

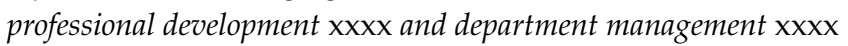

Pedagogical Content Knowledge, $\mathrm{xxxx}$ the explicit recognition of the interaction between knowledge of content, knowledge of teaching and knowledge of learning Curriculum change, $\mathrm{xxxx}$, official policy $\mathrm{xxxx}$, teacher response $\mathrm{xxxx}$, student choice $\mathrm{xxxx}$

\section{Research in Science Education $\mathrm{xxxx}$}

high school students doing science internships $\mathrm{xxxx}$, directly interacting with scientists xxxx;

dealing with scientific work $\mathrm{xxxx}$, factors that encourage scientific careers $\mathrm{xxx \textrm {x }}$ History and Nature of Science issues $\mathrm{xxxx}$ concerning modelling $\mathrm{xxxx}$, methods $\mathrm{xxxx}$, cultural influences $\mathrm{xxxx}$, connections with learning difficulties $\mathrm{xxx \textrm {x }}$ 


\section{Appendix B. Analysis Sub-Category Data}

\begin{tabular}{|c|c|c|c|c|c|c|}
\hline Type of Paper ${ }^{1}$ & 2005-2009 $(n=955)$ & $R^{2}$ & 2010-2014 $(n=1339)$ & $R^{2}$ & 2005-2014 $(n=2294)$ & $R^{3}$ \\
\hline Empirical & $799(83.66 \%)$ & 1 & $490(36.59 \%)$ & 1 & $1289(56.19 \%)$ & 1 \\
\hline Position Paper & $68(7.12 \%)$ & 2 & $176(13.14 \%)$ & 2 & $244(10.64 \%)$ & 2 \\
\hline Theoretical Paper & $27(2.83 \%)$ & 4 & $22(1.64 \%)$ & 4 & $49(2.14 \%)$ & 4 \\
\hline Review & $50(5.24 \%)$ & 3 & $68(5.08 \%)$ & 3 & $118(5.14 \%)$ & 3 \\
\hline \multicolumn{7}{|l|}{ Research Methodology } \\
\hline Qualitative & $458(47.96 \%)$ & 1 & $287(21.43 \%)$ & 1 & $745(32.48 \%)$ & 1 \\
\hline Quantitative & $217(22.72 \%)$ & 2 & $118(8.81 \%)$ & 2 & $335(14.60 \%)$ & 2 \\
\hline Mixed Method & $124(12.98 \%)$ & 3 & $85(6.35 \%)$ & 3 & $209(9.11 \%)$ & 3 \\
\hline \multicolumn{7}{|l|}{ Level } \\
\hline Secondary & $266(27.85 \%)$ & 1 & $452(33.76 \%)$ & 1 & $718(31.30 \%)$ & 1 \\
\hline Post-secondary & $127(13.30 \%)$ & 3 & $279(20.84 \%)$ & 2 & $406(17.70 \%)$ & 2 \\
\hline Primary & $143(14.97 \%)$ & 2 & $239(17.85 \%)$ & 3 & $382(16.65 \%)$ & 3 \\
\hline Early Childhood & $24(2.51 \%)$ & 4 & $21(1.57 \%)$ & 4 & $45(1.96 \%)$ & 4 \\
\hline \multicolumn{7}{|l|}{ Discipline } \\
\hline Physics & $127(13.30 \%)$ & 1 & $182(13.59 \%)$ & 1 & $309(13.47 \%)$ & 1 \\
\hline Biology & $111(11.62 \%)$ & 2 & $178(13.29 \%)$ & 2 & $289(12.60 \%)$ & 2 \\
\hline Chemistry & $99(10.37 \%)$ & 3 & $138(10.31 \%)$ & 3 & $237(10.33 \%)$ & 3 \\
\hline Environmental \& Marine Science & $20(2.09 \%)$ & 4 & $77(5.75 \%)$ & 4 & $97(4.23 \%)$ & 4 \\
\hline Geology & $20(2.09 \%)$ & 4 & $19(1.42 \%)$ & 5 & $39(1.70 \%)$ & 5 \\
\hline \multicolumn{7}{|l|}{ Scientific Literacy } \\
\hline Access & $238(24.90 \%)$ & 1 & $296(22.10 \%)$ & 1 & $534(23.28 \%)$ & 1 \\
\hline Engagement & $180(18.82 \%)$ & 2 & $323(24.10 \%)$ & 2 & $503(21.93 \%)$ & 2 \\
\hline Application & $104(10.90 \%)$ & 3 & $50(3.73 \%)$ & 3 & $154(6.71 \%)$ & 3 \\
\hline \multicolumn{7}{|l|}{ Teaching Approaches } \\
\hline Strategies & $185(19.40 \%)$ & 1 & $203(15.20 \%)$ & 1 & $388(16.91 \%)$ & 1 \\
\hline Practical work & $77(8.06 \%)$ & 2 & $118(8.81 \%)$ & 2 & $195(8.50 \%)$ & 2 \\
\hline $\begin{array}{l}\text { Information \& Communication Technology } \\
\text { (ICT) }\end{array}$ & $66(6.91 \%)$ & 4 & $93(6.95 \%)$ & 3 & $159(6.93 \%)$ & 3 \\
\hline Assessment & $75(7.85 \%)$ & 3 & $84(6.27 \%)$ & 4 & $159(6.93 \%)$ & 3 \\
\hline $\begin{array}{l}\text { Informal Science Education } \\
\text { Learning Focus }\end{array}$ & $65(6.81 \%)$ & 4 & $69(5.15 \%)$ & 5 & $134(5.84 \%)$ & 5 \\
\hline Constructivism & $288(30.20 \%)$ & 1 & $172(12.80 \%)$ & 1 & $460(20.05 \%)$ & 1 \\
\hline
\end{tabular}




\begin{tabular}{|c|c|c|c|c|c|c|}
\hline Type of Paper ${ }^{1}$ & $2005-2009(n=955)$ & $R^{2}$ & 2010-2014 $(n=1339)$ & $R^{2}$ & 2005-2014 $(n=2294)$ & $R^{3}$ \\
\hline Learner attitudes & $160(16.80 \%)$ & 2 & $165(12.30 \%)$ & 2 & $325(14.17 \%)$ & 2 \\
\hline Theories & $130(13.60 \%)$ & 3 & $56(4.18 \%)$ & 3 & $186(8.11 \%)$ & 3 \\
\hline \multicolumn{7}{|l|}{ Teacher } \\
\hline ... Preparation & $160(16.80 \%)$ & 1 & $94(7.02 \%)$ & 1 & $254(11.07 \%)$ & 1 \\
\hline ... Pedagogical Content Knowledge (PCK) & $153(16.00 \%)$ & 2 & $60(4.48 \%)$ & 2 & $213(9.29 \%)$ & 2 \\
\hline ... Curriculum Change & $100(10.50 \%)$ & 3 & $52(3.88 \%)$ & 4 & $152(6.63 \%)$ & 3 \\
\hline ... Professional Development & $55(5.76 \%)$ & 4 & $59(4.41 \%)$ & 2 & $114(4.97 \%)$ & 4 \\
\hline Research on Science Education Research & $49(5.13 \%)$ & 5 & $44(3.29 \%)$ & 5 & $93(4.05 \%)$ & 5 \\
\hline \multicolumn{7}{|l|}{ Science and Education } \\
\hline History and Nature of Science (HNS) & $109(11.40 \%)$ & 1 & $145(10.80 \%)$ & 1 & $254(11.07 \%)$ & 1 \\
\hline Relationship of Science \& Education & $48(5.03 \%)$ & 2 & $69(5.15 \%)$ & 2 & $117(5.10 \%)$ & 2 \\
\hline
\end{tabular}

Notes: ${ }^{1}$ Readers should recall that articles are 'double coded', that is the content of a single article may place it in more than one category. $(\%=$ Number of abstracts coded into sub-category/total number of articles coded $\left.{ }^{*} 100\right) ;{ }^{2}$ Proportional Rank for sub-category in these journals across five years; ${ }^{3}$ Proportional Rank for sub-category in these journals across ten years.

\section{Appendix C. A Deeper Look at 'Conceptual Change' within ‘Constructivism'}

\begin{tabular}{cccccccccccccccc}
\hline Journal & \multicolumn{3}{c}{ IJSE } & \multicolumn{3}{c}{ JRST } & \multicolumn{3}{c}{ RiSE } & \multicolumn{3}{c}{ ScEd } \\
\hline Time span & $05-09$ & $10-14$ & $\mathbf{0 5 - 1 4}$ & $05-09$ & $10-14$ & $\mathbf{0 5 - 1 4}$ & $05-09$ & $10-14$ & $\mathbf{0 5 - 1 4}$ & $05-09$ & $10-14$ & $\mathbf{0 5 - 1 4}$ & $05-09$ & $10-14$ & $\mathbf{0 5 - 1 4}$ \\
Total articles & 300 & 577 & $\mathbf{8 7 7}$ & 250 & 251 & $\mathbf{5 0 1}$ & 150 & 274 & $\mathbf{4 2 4}$ & 233 & 206 & $\mathbf{4 3 9}$ & 22 & 31 & $\mathbf{5 3}$ \\
Learning articles & 240 & 187 & $\mathbf{4 2 7}$ & 174 & 64 & $\mathbf{2 3 8}$ & 91 & 65 & $\mathbf{1 5 6}$ & 61 & 73 & $\mathbf{1 3 4}$ & 12 & 4 & $\mathbf{1 3}$ \\
Constructivism & 103 & 99 & $\mathbf{2 0 2}$ & 75 & 15 & $\mathbf{9 0}$ & 55 & 20 & $\mathbf{7 5}$ & 15 & 5 & $\mathbf{2 0}$ & 5 & 1 & $\mathbf{6}$ \\
Concept. Change & 23 & 4 & $\mathbf{2 7}$ & 19 & 2 & $\mathbf{2 1}$ & 23 & 0 & $\mathbf{2 3}$ & 3 & 0 & $\mathbf{3}$ & 1 & 0 & $\mathbf{1}$ \\
Learning/Total & $\mathbf{0 . 8 0}$ & $\mathbf{0 . 3 2}$ & 0.49 & $\mathbf{0 . 7 0}$ & $\mathbf{0 . 2 6}$ & 0.48 & $\mathbf{0 . 6 1}$ & $\mathbf{0 . 2 4}$ & 0.37 & $\mathbf{0 . 2 6}$ & $\mathbf{0 . 3 5}$ & 0.31 & $\mathbf{0 . 5 5}$ & $\mathbf{0 . 1 3}$ & 0.30 \\
Const/Learning & $\mathbf{0 . 4 3}$ & $\mathbf{0 . 5 3}$ & 0.47 & $\mathbf{0 . 4 3}$ & $\mathbf{0 . 2 3}$ & 0.38 & $\mathbf{0 . 6 0}$ & $\mathbf{0 . 3 1}$ & 0.48 & $\mathbf{0 . 2 5}$ & $\mathbf{0 . 0 7}$ & 0.15 & $\mathbf{0 . 4 2}$ & $\mathbf{0 . 2 5}$ & 0.38 \\
Conceptual Change/Constructivism & $\mathbf{0 . 2 2}$ & $\mathbf{0 . 0 4}$ & 0.13 & $\mathbf{0 . 2 5}$ & $\mathbf{0 . 1 3}$ & 0.23 & $\mathbf{0 . 4 2}$ & $\mathbf{0 . 0 0}$ & 0.31 & $\mathbf{0 . 2 0}$ & $\mathbf{0 . 0 0}$ & 0.15 & $\mathbf{0 . 2 0}$ & $\mathbf{0 . 0 0}$ & 0.17 \\
Conceptual Change/Total & $\mathbf{0 . 0 8}$ & $\mathbf{0 . 0 1}$ & 0.03 & $\mathbf{0 . 0 8}$ & $\mathbf{0 . 0 1}$ & 0.04 & $\mathbf{0 . 1 5}$ & $\mathbf{0 . 0 0}$ & 0.05 & $\mathbf{0 . 0 1}$ & $\mathbf{0 . 0 0}$ & 0.01 & $\mathbf{0 . 0 5}$ & $\mathbf{0 . 0 0}$ & 0.02 \\
\hline
\end{tabular}




\section{References}

1. Snow, C.P. The Two Cultures, with an Introduction by Stefan Collini; Cambridge University Press: Cambridge, $\mathrm{UK}, 1998$.

2. Chang, Y.-H.; Chang, C.-Y.; Tseng, Y.-H. Trends in Science Education research: An automatic content analysis. J. Sci. Educ. Technol. 2010, 19, 315-331. [CrossRef]

3. Yeh, Y.-F.; Jen, T.-H.; Hsu, Y.-S. Major strands in scientific inquiry through cluster analysis of research abstracts. Int. J. Sci. Educ. 2012, 34, 2811-2842. [CrossRef]

4. Taylor, J.; Furtak, E.; Kowalski, S.; Martinez, A.; Slavin, R.; Stuhlsatz, M.; Wilson, C. Emergent themes from recent research syntheses in Science Education and their implications for research design replication and reporting practices. J. Res. Sci. Teach. 2016, 53, 1216-1321. [CrossRef]

5. Bennett, J.; Lubben, F.; Hogarth, S.; Campbell, B. Systematic reviews of research in Science Education: Rigour or rigidity? Int. J. Sci. Educ. 2005, 27, 387-416. [CrossRef]

6. Rennie, L.J. Guest editorial: Improving the interpretation and reporting of quantitative research. J. Res. Sci. Teach. 1998, 35, 237-248. [CrossRef]

7. Eybe, J.; Schmidt, H.-J. Quality criteria and exemplary papers in chemistry education research. Int. J. Sci. Educ. 2001, 23, 209-225. [CrossRef]

8. Tsai, C.-C.; Wen, M.L. Research and trends in Science Education from 1998 to 2002: A content analysis of publication in selected journals. Int. J. Sci. Educ. 2005, 27, 3-14. [CrossRef]

9. Ritchie, S.M. The World of Science Education: Handbook of Research in Australasia; Sense Publishers: Rotterdam, The Netherlands, 2009.

10. Lee, M.-H.; Wu, Y.-T.; Tsai, C.-C. Research trends in Science Education from 2003 to 2007: A content analysis of publications in selected journals. Int. J. Sci. Educ. 2009, 31, 1999-2020. [CrossRef]

11. Lin, T.-C.; Lin, T.-J.; Tsai, C.-C. Research trends in Science Education from 2008 to 2012: A systematic content analysis of publications in selected journals. Int. J. Sci. Educ. 2014, 36, 1346-1372. [CrossRef]

12. O'Toole, J.M.; McKoy, K.S. What's hot (or not)?: A five year survey of research in science education. In Proceedings of the ASERA 41st Annual Conference, Newcastle, UK, 30 June-3 July 2010; pp. 61-62.

13. Major, C.H.; Savin-Baden, M. An Introduction to Qualitative Research Synthesis; Routledge: London, UK, 2010.

14. Light, R.; Adams, J. Knowledge in motion: The evolution of HIV/AIDS research. Scientometrics 2015. [CrossRef]

15. Zohar, A.; Barzilai, S. A review of research on metacognition in science education: Current and future directions. Stud. Sci. Educ. 2013, 49, 121-169. [CrossRef]

16. Furtak, E.M.; Sedel, T.; Iverson, H.; Briggs, D.C. Experimental and quasi-experimental studies of inquiry-based science teaching: A. meta-analysis. Rev. Educ. Res. 2012, 82, 300-329. [CrossRef]

17. Rudolph, J.L. Historical writing on Science Education: A view of the landscape. Stud. Sci. Educ. 2008, 43, 63-82. [CrossRef]

18. Ronda-Pupo, G.A.; Katz, J.S. The scaling relationship between citation-based performance and international collaboration of Cuban articles in natural sciences. Scientometrics 2015. [CrossRef]

19. Jenkins, E.W. Research in science education: Time for a health check? Stud. Sci. Educ. 2000, 35, 1-26. [CrossRef]

20. Minner, D.D.; Levy, A.J.; Century, J. Inquiry-based Science instruction-What is it and does it matter? Results from a research synthesis Years 1984 to 2002. J. Res. Sci. Teach. 2010, 47, 474-496.

21. Slavin, R.E.; Lake, C.; Hanley, P.; Thurston, A. Experimental evaluations of elementary science programs: A best-evidence synthesis. J. Res. Sci. Teach. 2014, 51, 870-901. [CrossRef]

22. Bondi, M.; Sanz, R.L. (Eds.) Abstracts in Academic Discourse: Variation and Change; Peter Lang: Bern, Switzerland, 2014.

23. Bredo, E. Getting over the methodology wars. Educ. Res. 2009, 38, 441-448. [CrossRef]

24. Howe, K.R. Positivist dogmas, rhetoric and the education science question. Educ. Res. 2009, 38, 428-440. [CrossRef]

25. Wandersee, J.H.; Demastes, S. An Analysis of the Relative Success of Qualitative and Quantitative Manuscripts Submitted to the Journal of Research in Science Teaching. J. Res. Sci. Teach. 1992, 29, 1005-1010. [CrossRef] 
26. Abd-El-Khalick, F.; Zeidler, D.L. On the 'fabric' of our global science education research community: The art and science of writing for the Journal of Research in ScienceTeaching. J. Res. Sci. Teach. 2016, 53, 3-6. [CrossRef]

27. Gunstone, R.F.; Treagust, D.F. Conceptual change in science: Research at the forefront over the past three decades. In The World of Science Education: Handbook of Research in Australasia; Ritchie, S.M., Ed.; Sense Publishers: Rotterdam, The Netherlands, 2009; Chapter 11; pp. 185-198.

28. Hand, B.; Yore, L.D.; Jagger, S.; Prain, V. Connecting research in science literacy and classroom practice: A review of science teaching journals in Australia, the UK and the United States, 1998-2008. Stud. Sci. Educ. 2010, 46, 45-68. [CrossRef]

29. Fensham, P.J. The forest and the woodchips: Are they alternative paradigms for studying the tree of science education? Res. Sci. Educ. 1979, 9, 43-53. [CrossRef]

(C) 2018 by the authors. Licensee MDPI, Basel, Switzerland. This article is an open access article distributed under the terms and conditions of the Creative Commons Attribution (CC BY) license (http://creativecommons.org/licenses/by/4.0/). 